\title{
As experiências latino-americanas na busca por autonomia: um exercício analítico pela ótica da economia política internacional e do pensamento social latino-americano
}

\author{
Mariana Davi Ferreira ${ }^{1}$ e Jaime Cesar Coelho ${ }^{2}$
}

\begin{abstract}
1 Mestre em Relações Internacionais pelo Programa de Pós-Graduação em Relações Internacionais (UFSC), Bacharel em Relações Internacionais (UEPB) e concluinte do curso de Bacharelado em Ciências Sociais (UFPB). Professora do curso de Bacharelado em Relações Internacionais da Universidade Federal do Amapá. E-mail: marianadaviferreira@gmail.com

2 Doutorado em Ciências Sociais pela Universidade Estadual de Campinas, Mestrado em Sociologia Política e graduaddo em Ciências Econômicas. Professor do Departamento de Economia e Relações Internacionais da Universidade Federal de Santa Catarina (UFSC) e do Programa de Pós-Graduação em Relações Internacionais da mesma instituição. E-mail: jccoelho@ineu.org.br
\end{abstract}

RESUMO: O presente artigo objetiva analisar o cenário no qual emergem as transformações políticas e econômicas que marcam a América Latina no limiar do século XXI, a partir de movimentações que apontam para a busca por maior autonomia frente à condição de dependência estrutural que demarca a região. Neste sentido, compreendemos tais processos de busca de autonomia como respostas às experiências neoliberais dos anos 1990. Partimos do quadro analítico-conceitual da Teoria Marxista da Dependência (TMD) para apreensão dos determinantes estruturais da dependência latino-americana e dos condicionantes conjunturais que possibilitaram uma maior autonomia a essas economias dependentes, resultando nas atuais experiências alternativas em curso na região. Tomando estes aspectos como referenciais, primeiramente realizamos uma discussão acerca da necessidade do reconhecimento da contribuição da TMD no campo da Economia Política Internacional, para a análise da realidade latinoamericana. Em seguida, retomamos algumas categorias da TMD que apontam para o papel que a América Latina cumpre no processo de acumulação capitalista. Logo, estabelecemos uma interlocução entre os determinantes estruturais da dependência latino-americana e as alterações advindas do processo de financeirização, que origina uma nova fase histórica da dependência. Por fim, indicamos os aspectos conjunturais que possibilitaram a ascensão de experiências alternativas em alguns países da América Latina, tendo como foco de trabalho o conceito de autonomia das economias periféricas sobre os condicionantes estruturais da dependência.

Palavras-chave: América Latina; capitalismo; autonomia; dependência.

Latin american experiences in the plight for autonomy: an analytical exercise through international political economy and social latin american thinking

ABSTRACT: The present article aims to analyze the context in which have taken place the political and economic transformations that characterized Latin American in the beginning of the 21st century, focusing on the struggle for more autonomy in opposition to the structural dependence which demarcates the region. Therefore, we comprehend these processes of struggle for autonomy as a direct opposition to the neoliberalism of the 90s. The conceptual framework of Marxist Dependency Theory offers the paradigm to understand the structural determinants of Latin American dependency and the conjunctural conditioners that have made possible a somewhat bigger autonomy, within the dependency, to these dependent economies, which have resulted in the contemporary alternative experiences in course in the region. Taking these aspects as references, firstly there is a discussion about the need to 
acknowledge Marxist Dependency Theory contributions to the International Political Economy field in the analysis of latin american reality. Following, some conceptual categories of Marxist Dependency Theory, which point to the role played by Latin American in the capitalist accumulation process, are resumed. Then, there is observed an interlocution between the structural determinants of Latin American dependency and the changes produced by financialization, which originates a new historical phase of dependency. Finally, there is indication of the conjunctural aspects that have made possible the rise of alternative experiences in some of Latin American countries, focusing the concept of autonomy of the peripheral economies on the structural conditioners of dependency.

Keywords: Latin America; capitalismo; autonomy; dependency.

\section{INTRODUÇÃO}

Depois de quase uma década de governos de esquerda e centro-esquerda na América Latina ${ }^{1}$ e da retomada do projeto neoliberal em algumas economias importantes da região, notadamente Argentina e Brasil, pergunta-se qual foi o alcance e os limites dos projetos de autonomia regional desenvolvidos por esses governos sob a ótica de seus constrangimentos estruturais. Em outros termos: qual a autonomia possível na região? Entende-se autonomia como a capacidade dos governos locais em gerir as políticas públicas desde o processo de tomada de decisão até a sua execução, em maior ou menor conformidade com os condicionamentos externos. Supõe-se que a autonomia é um exercício relativo de poder, posto que se trata da ação coletiva de unidades nacionais que se inserem numa ordem global. Assim sendo, falamos em grau de autonomia e não na autonomia como um sinônimo de independência diante dos constrangimentos externos. $O$ esforço analítico aqui contido se expressa, em linhas gerais, na necessidade de compreender os elementos conjunturais e estruturais sob os quais se erigiram tais processos de

\footnotetext{
${ }^{1}$ Neste artigo, usaremos o termo América Latina em referência aos Estados que compõem a América do Sul, América Central e o Caribe, ou seja, todos os países da região americana, que se situam ao sul do Rio Grande, no México.
}

busca por autonomia, partindo de um arcabouço teórico do pensamento social latinoamericano e da Economia Política Internacional (EPI).

Entre os anos finais da década de 1990 e início dos anos 2000, as consequências do processo de ajustamento (COELHO, 2012) começaram a produzir efeitos cumulativos e progressivos de desgaste dos governos neoliberais. Com a perda de legitimidade desses governos, inicia-se um processo de transformações que se centram, de maneira conjuntural, em torno do questionamento desses ajustes. Estas transformações emergem com a retomada da força dos partidos políticos, organizações de esquerda e das lutas dos movimentos sociais, resultando na eleição de chefes de Estado de cunho progressista em alguns países. Os rearranjos políticos promovidos no cenário latinoamericano interferem no posicionamento da região no sistema internacional. A retomada deste bloco de poder, desarticulado durante a hegemonia do neoliberalismo na região na década de 1990, ressurge conformando um bloco antineoliberal, a partir da construção de alternativas, que também se expressam nos projetos para integração regional para a América Latina.

Neste contexto, a emergência de líderes progressistas por vias democráticas em alguns Estados latino-americanos cumpre um 
importante papel no esforço na construção de uma articulação entre os governos para uma inserção mais autônoma da região no cenário internacional. Podemos considerar a eleição de Hugo Chávez como presidente da Venezuela, em 1998, um marco inicial na inflexão da política regional. Assim, a ascensão de lideranças como Hugo Chávez na Venezuela, Evo Morales na Bolívia, Fernando Lugo no Paraguai, Rafael Correa no Equador, Nestor Kirchner na Argentina, Mujica no Uruguai e Lula no Brasil, resultam de um rechaço popular às políticas neoliberais, em especial aos seus efeitos sociais como desemprego, baixos salários e falta de perspectivas, em especial para os mais jovens. Importante frisar que esses governos não adotam políticas homogêneas, mesmo porque emergem em condições políticas específicas de seus Estados nacionais. Essas especificidades aparecerão em discursos e ações que guardam maior ou menor grau de assertividade contra o sistema. Encontraremos aí posturas claramente assertivas que destacam a relação entre o neoliberalismo e o imperialismo, o caso dos governos de Chávez e Morales é claro neste sentido, até posturas mais conciliatórias e moderadas como a de Lula no Brasil.

Apesar destas clivagens, trabalha-se com a hipótese da convergência de interesses entre estes governos, em especial, no sentido da construção de uma maior autonomia regional. Isto pode ser visto na atuação externa em temas sensíveis como regras de investimento e propriedade intelectual. A segunda hipótese é que a fragilidade das coalisões de poder local foram agravadas pelo lento processo de integração, o que tornou as unidades mais frágeis diante da reversão do ciclo de negócios internacional, com a queda do preço das commodities, variável importante para a autonomia de países que tem nestes itens papel preponderante nas pautas de exportação. Na crise, como sempre, crescem as pressões e a influência externa.

O quadro teórico-conceitual dos clássicos da Economia Política Internacional e da Teoria Marxista da Dependência (TMD) nos possibilita observar os condicionantes estruturais da dependência econômica sob a qual se formaram os Estados latinoamericanos e as particularidades conjunturais nas quais emergiram as experiências alternativas em curso em alguns Estados da região. Compreendendo que a condição periférica das economias latino-americanas a situam em situações de constrangimento externo que podem cercear a construção de margem de manobra na região. Destarte, a apreensão da dimensão conjunta entre política e economia torna-se central para compreender as experiências latinoamericanas contemporâneas sob a perspectiva de totalidade. Assim, nas páginas seguintes, nosso esforço consiste em caracterizar, o cenário que permitiu essas mudanças, na busca de avançar na compreensão desse processo.

Tomando estes aspectos como referenciais, nosso objetivo teórico consiste em estabelecer uma interlocução entre os determinantes estruturais da dependência latinoamericana e as alterações na conjuntura, sob as quais se desenvolveram as experiências por busca da autonomia regional. Para tanto, retomamos inicialmente alguns elementos da formação econômica da América Latina, assinalando o papel que essa cumpre na reprodução ampliada de capital. Em seguida, situamos o estágio monopolista, que traduz inflexões no modo de produção capitalista, em especial, na etapa hegemo- 
nizada pelo capital financeiro. Por fim, indicamos os aspectos conjunturais que possibilitaram a emergência de experiências alternativas em alguns países da América Latina. Para tal, partimos do suposto de que variações conjunturais do ciclo de negócios internacional possibilitam uma "margem de manobra" às economias periféricas sob os condicionantes estruturais da dependência, que possibilitaram aumento do grau de autonomia por esses Estados no contexto analisado.

\section{A CRÍTICA À ECONOMIA POLÍTICA E A COMPREENSÃO DA CONDIÇÃO DA DEPEN- DÊNCIA DAS ECONOMIAS LATINO-} AMERICANAS

Umas das tragédias das interpretações dos problemas econômicos reais foi a separação, já no século XIX, entre os campos da economia e da política. O marco dessa especialização se dá pela emergência da Economia Neoclássica na segunda metade do século XIX. Na longa trajetória do século XX, entre sínteses e reinterpretações, entre esquecimentos e questionamentos, a economia neoclássica ressurgirá com força durante a acirramento da Guerra Fria e a partir da crise do Estado de Bem Estar, que se dá com a crise dos 1970 por meio do aparecimento do fenômeno simultâneo da estagnação e inflação nos países centrais. Desde então o "imperialismo da teoria neoclássica" em quase todas as ciências sociais é um fato.

Uma das principais críticas à teoria neoclássica é que sob o manto da formalização, da matematização, ela encobre seu caráter ideológico de defesa do laissez-faire, de combate sistemático às políticas de bemestar e de questionamento total às políticas distributivas. Problemas como a centralização e concentração do capital são colocados para debaixo do tapete ou são tratados como resultados de políticas ruins de interferência estatal (FOSTER; MACCHESNAY, 2012). Para os neoclássicos os mercados são eficientes e os atores são racionais. Numa era de rivalidade interestatal crescente e de monopolização do capital, o domínio da teoria neoclássica na ciência econômica só pode se explicar por seu apelo ideológico e pela forma como se constroem os discursos científicos. Como lembra Robert W. Cox (1981): os discursos são feitos por alguém para alguém. Eles são ao mesmo tempo representação de interesses e organizadores de interesses. A vitória da teoria neoclássica é, portanto, a vitória do monetarismo e do liberalismo sobre o pensamento crítico e as políticas de bem-estar. Representará, posteriormente, a vitória sobre o pensamento crítico periférico e as tentativas da construção de projetos autônomos de desenvolvimento.

Como explicar o aparecimento da Economia Política Internacional neste contexto de refluxo da economia política? Como uma resposta aos desafios reais que se apresentavam e que não encontravam mais espaço para investigação nos departamentos de economia, ressalvando-se que se tratava de uma resposta dentro do sistema, dentro dos cânones acadêmicos. Dito de maneira mais contextual, a emergência do campo da Economia Política Internacional é uma resposta ao crescente domínio da teoria neoclássica nos departamentos de economia dos Estados Unidos da América (EUA) e da Inglaterra anos 1960 e 1970 . Ela surge nos departamentos de ciência política nos EUA e na Inglaterra. De certa forma isto evidencia que a discussão dos problemas reais, 
integrando as análises política e econômica tinham forte resistência nos departamentos de economia. A Guerra Fria praticamente expulsara o marxismo e a economia política crítica das universidades estadunidenses. Mesmo o keynesianismo, corrente importante e de grande influência no imediato pós-guerra, havia sido deglutido pela síntese neoclássica.

Mas o fato é que a realidade batia à porta da universidade. A década de 1970 é marcada por mudanças substanciais na ordem econômica internacional, mudanças na hegemonia americana, retorno das economias do Japão e dos países da Europa Ocidental, descolonização no pós-Guerra, a crise do petróleo e a financeirização (expansão do mercado privado de crédito e desregulamentação financeira com abertura das contas de capital), que trouxeram novos dilemas e desafios ao desenvolvimento econômico. (COHEN, 2008, p. 22).

A resposta anglo-saxã para a cegueira da ciência econômica aos desafios da política e do poder internacionais viria por meio da apropriação pelo novo campo da Economia Política Internacional de temas caros aos debates sobre o desenvolvimento, como por exemplo a temática da interdependência. Iria se desenvolver tratando dos regimes internacionais e dos problemas da governança e, no início, algo que seria praticamente abandonado nas décadas seguintes, trataria de grandes questões como a mudança da ordem internacional e seus elementos explicativos.

Contudo, ao traçar-se a história intelectual da economia política internacional não se deve omitir que uma vibrante e profícua literatura sobre o tema se desenvolvia fora do mainstream intelectual, à margem das universidades do centro e dos formadores de opinião.

Nesse sentido, é importante retomar o lugar de contribuição da produção vinculada ao campo da Economia Política Marxista para compreensão das relações internacionais, recuperando teóricos clássicos vinculados ao marxismo como Vladmir Lenin, Rosa Luxemburgo e Antonio Gramsci. Também é importante que não se omita a decisiva contribuição dos estudos do pensamento social latino americano, que já no imediato pós guerra trariam ao centro do debate o problema das trocas desiguais. Pensando a especificidade latinoamericana, torna-se imprescindível destacar a contribuição do pensamento desenvolvido no interior da Comissão Econômica para América Latina e Caribe (CEPAL), com destaque para Prebisch e Celso Furtado. E, posteriormente, o grande debate em torno do subdesenvolvimento e da dependência latino-americana travado na segunda metade do século $X X$, ao qual estiveram vinculados Celso Furtado, Florestan Fernandes, Octavio Ianni, Theotonio dos Santos, Ruy Mauro Marini, entre outros. Esses teóricos contribuíram para compreender as relações econômicas internacionais a partir de chaves analíticas como o imperialismo, a relação centro-periferia, a dinâmica do capitalismo dependente e a particularidade da sociedade de classes latino-americana.

Sugere-se neste artigo que uma economia política internacional que procure verificar os reais problemas da ordem internacional deve ser erguida não só por uma epistemologia que tem na ontologia dos problemas dos países o terreno fértil. Daí a importância em revelar e afirmar simultaneamente que para além do pensamento neoclássico e seus desdobramentos interpretativos no mainstream da ciência social, 
desenvolveu-se um pensamento crítico rico e muito profícuo que pode inspirar as análises do presente.

\subsection{A Teoria Marxista da Dependência e a necessidade de seu resgate}

Dentro do que se pode chamar de pensamento herético, que compõe o amplo arcabouço da teoria crítica sobre o desenvolvimento e do pensamento social latinoamericano, destaca-se aqui alguns elementos da Teoria Marxista da Dependência. Carcanholo (2013, p. 192) a define como:

a versão que interpreta, com base na teoria de Marx sobre o modo de produção capitalista, na teoria clássica do imperialismo e em algumas outras obras pioneiras sobre a relação centro-periferia na economia mundial, a condição dependente das sociedades periféricas como um desdobramento próprio da lógica de funcionamento da economia capitalista mundial

Nesta perspectiva, o desenvolvimento histórico do capitalismo não se deu de modo homogêneo ou linear. "A história do subdesenvolvimento latino-americano é a história do desenvolvimento do sistema capitalista mundial". Ruy Mauro Marini (1970, p. 03, tradução nossa) inicia sua obra Subdesarrollo y revolución com essa afirmação, que nos faz perceber a ligação entre a formação sócio-histórica da América Latina e sua situação de dependência como parte essencial da expansão do capitalismo mundial. Isso porque a exploração da riqueza do subcontinente latino-americano, por meio da expansão europeia, foi fundamental para o processo de acumulação originária do capital.

Para que a crescente tendência de universalização do modo de produção capitalista caracterizasse uma realidade concreta, foi funcional o processo de colonização do território, que hoje conforma a América Latina. O violento processo de expropriação das riquezas da América Latina contribuiu para a consolidação do modo de produção capitalista, por meio da acumulação originária do capital. Marx (2002) expõe de maneira objetiva - no capítulo XXIV d'O Capital - A chamada acumulação primitiva - o papel essencial da colonização do "Novo Mundo" para a consolidação do modo de produção capitalista por meio da acumulação primitiva:

[...] As descobertas de ouro e de prata na América, o extermínio, escravização das populações indígenas, forçadas a trabaIhar no interior das minas, o início da conquista e pilhagem das Índias Orientais e a transformação da África num vasto campo de caçada lucrativa são os acontecimentos que marcam os albores da era da produção capitalista. Estes processos idílicos são fatores fundamentais da acumulação primitiva (MARX, 2002, p. 684).

A América Latina conforma-se, assim, sob o signo da dependência de raiz estrutural.

No campo analítico emerge, no início da década de 1970, a TMD como uma corrente do pensamento marxista que, com base em indagações históricas e políticas, toma para si a tarefa (não só acadêmica, mas política ${ }^{2}$ ) de entender a inserção subordinada das economias latino-americanas na divisão internacional do trabalho (DIT).

\footnotetext{
${ }^{2}$ Prova disso, é a fundação da Organização Revolucionária Política Operária (Polop).
} 
Dialética da Dependência, texto redigido por Ruy Mauro Marini em 1973, é considerado por muitos como o marco inaugural da versão marxista da Teoria da Dependência ${ }^{3}$. De acordo com essa linha interpretativa, o estudo das formações sociais concretas da América Latina deve definir as determinações que se encontram na base da luta de classes desenvolvida entre nós, que expressa nuances particulares se comparadas aos países centrais que vivenciaram, majoritariamente, as clássicas revoluções burguesas.

É necessário considerar que o arcabouço explicativo da interpretação marxista sobre a dependência se constituiu na dinâmica do debate conjuntural sobre o desenvolvimento naquele momento. Um debate que tem um mundo em ebulição e onde a perspectiva revolucionária era animada pela Revolução Cubana (1959) e pelas inúmeras guerrilhas de libertação de caráter nacional e anti-imperialista em curso na América Latina e mundo afora. Neste contexto, as formulações que resultaram na TMD tomaram fôlego a partir de duas críticas na seara política: por um lado, a rejeição às teses defendidas pela Comissão Econômica para a América Latina e Caribe (CEPAL) e, por outro, as críticas feitas ao Partido Comunista Brasileiro (PCB). Para a CEPAL, um elemento como a pobreza, por exemplo, poderia ser superado com o amplo desenvolvimento industrial e com o efetivo dinamismo do mercado interno. Já o PCB, influenciado pelas análises eurocêntricas do stalinismo e sustentado na tese da "burguesia nacional", avaliava

${ }^{3}$ Autores como Vania Bambirra, Theotônio dos Santos e André Gunder Frunk, Orlando Caputo e Roberto Pizarro não só impulsionaram a TMD em seu início, como também lançaram os fundamentos teóricos basilares para desvendar as leis (isto é, as tendências históricas) que determinam a dinâmica da economia dependente. naquela conjuntura histórica que a revolução burguesa seria uma etapa necessária para a revolução proletária.

A síntese construída pela TMD tem como

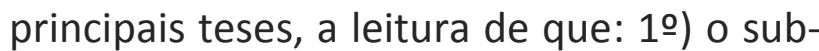
desenvolvimento é parte constitutiva da dinâmica capitalista e, portanto, é estrutural e insuperável no marcos da lógica do capitalismo e; 2 ㅇ) a categoria particularidade é central ao entendimento da formação social latino-americana, que possui um capitalismo sui generis. Desse modo, a história não pode ser mecanicamente reposta de um lugar para outro. Ignorar essa dimensão consiste, antes, na negação ou na redução da essência do materialismo históricodialético.

Para empreender uma análise de tamanha magnitude, a TMD constrói um arcabouço de categorias-chave para apresentar os fundamentos da economia dependente latino-americana. Em razão de nossos limites nos restringiremos, neste artigo, a algumas dessas categorias, são elas: transferência de valor, superexploração da força de trabalho e dependência.

Um aspecto elementar que caracteriza nossa dependência consiste no fato de que grande parcela de (mais) valor produzido na economia dependente não é devidamente apropriada por ela, mas pelas economias centrais (CARCANHOLO, 2013). Ou seja, na proporção em que se transfere valor da periferia para o centro se estabelece uma cisão no ciclo de reprodução do capital (MARINI, 2012).

Assim, a transferência de valor constituise como mecanismo estrutural na dinâmica das economias dependentes. Cabe ressaltar que o debate que a TMD trará sobre a transferência de valor tem relação com a tese das trocas desiguais desenvolvida na 
CEPAL, por meio de Prebisch, que inaugura seus trabalhos com um relatório sobre a questão. O que irá diferenciar a análise da TMD é a análise do valor, a partir da perspectiva marxista, e a forma como esta produção adquire características específicas nos países subdesenvolvidos. Diante da pulsão estrutural do excedente, a dinâmica do modo de produção capitalista na periferia pode encontrar formas de compensação, mesmo que estas formas no final das contas não resolvam o problema do desenvolvimento, ao contrário, tendam a criar um circulo estrutural de insuficiência de renda e mercado.

Marini (2005) aponta que o mecanismo de compensação introduzido para sanar essa interrupção da acumulação interna de capital nas economias latino-americanas é a superexploração da força de trabalho. 0 autor a define como uma forma de "compensar a perda de mais-valia, e que, incapaz de impedi-la no nível das relações de mercado, a reação da economia dependente é compensá-la no plano da produção interna" (MARINI, 2005, p. 154). Assim, a superexploração é uma lei própria da economia dependente e de sua reprodução em escala ampliada. É, portanto, um elemento constitutivo da realidade da América Latina, uma modalidade particular do capitalismo forjado entre nós, em sua essência, para atingir o objetivo derradeiro de todo e qualquer capitalista: o lucro, mais-dinheiro (D'). É o mecanismo utilizado pela classe burguesa da periferia para contrabalançar seu déficit na economia internacional.

Trata-se, dessa forma, "de aumentar simplesmente o trabalho excedente, que é aquele em que o operário continua produzindo depois de criar um valor equivalente ao dos meios de subsistência para seu pró- prio consumo" (Ibid., p. 154). Entretanto, a superexploração não se refere simplesmente à intensidade do trabalho; vai para além, uma vez que se torna demasiadamente complexa perante o baixo grau de desenvolvimento das forças produtivas verificado na economia dependente. Marini (2005) explica que:

[...] a intensificação do trabalho, a prolongação da jornada de trabalho e a expropriação da parte do trabalho necessário ao operário para repor sua força de trabalho - configuram um modo de produção fundado exclusivamente na maior produção do trabalhador, e não no desenvolvimento de sua capacidade produtiva. Isso é condizente com o baixo nível de desenvolvimento das forças produtivas na economia latino-americana, mas também os tipos de atividades que ali se realizam (MARINI, 2005, p. 156).

Destarte, cabe relacionar essa tendência particular do capitalismo dependente com uma tendência universal das relações sociais do modo de produção em vigor: a Lei Geral da Acumulação Capitalista, desvendada por Marx no capítulo XXIII d'O Capital. Para Amaral e Carcanholo (2012), essa lei guarda uma relação evidente com a economia dependente. A principal contradição que reside nessa tendência histórica observada por Marx é que, enquanto a produção é socializada sua distribuição é privada, gerando riqueza em um polo e miséria em outro.

Marx anota, ainda no capítulo supracitado, a dinâmica que faz emergir uma população relativamente supérflua, na qual se insere o Exército Industrial de Reserva. A relação entre superpopulação relativa e superexploração da força de trabalho é 
demonstrada por Carcanholo e Amaral (2012). Os autores apontam que

relacionar o EIR com a superexploração significa mostrar sua ação no sentido de exacerbar as formas ou mecanismos de extração da mais-valia. [...] Isso ocorre porque [...] a existência de uma massa de trabalhadores que se encontra excluída, à margem do mercado de trabalho (massa de desempregados), exerce uma pressão sobre aqueles trabalhadores que se encontram efetivamente empregados, forçando a que se submetam a todas as formas de superexploração existentes, sob pena de se verem substituídos e desempregados por 'trabalhadores da reserva' num momento futuro (2012, p. 100-1).

Theotônio dos Santos (2000) ressalta a existência de três períodos históricos para a dependência. A dependência colonial, que se configurava nas relações entre as metrópoles e as colônias. A dependência financeiro-industrial, que se desenvolve entre 0 final do século XIX e meados do século XX. E a dependência tecnológico-industrial, que vigora contemporaneamente, na qual as economias dependentes desde a primeira etapa de circulação da entrada de capital estrangeiro e no fornecimento de tecnologia externa para a etapa da produção.

A partir dos elementos apresentados, fica nítida a situação de dependência é condicionada estruturalmente pelas relações de transferência de valor estabelecidas no mercado internacional. Nesta linha, a superexploração, enquanto mecanismo de compensação, é uma necessidade para continuidade da acumulação de capital nas economias dependentes, que é o locus do modo de produção capitalista.
Assim sendo, compreendendo a dependência enquanto traço estrutural de sua formação sócio-histórica da América Latina, pode-se analisar a construção de autonomia e experiências alternativas nas economias dependentes como "margens de manobra" conjunturais. Neste sentido, uma alteração conjuntural nas trocas desiguais, como por exemplo o aumento do preço das commodities pode abrir espaço para uma maior autonomia dos governos dos países subdesenvolvidos. Claro, esta é uma possibilidade que será aproveitada conforme as características da coalizão de poder em cada país que vive esta conjuntura favorável. Essas "margens de manobra" permitem a diminuição relativa da situação de dependência dos países latino-americanos, porém, como apontado por Marini (2005), a única saída para o fim da situação de dependência dos países latino-americanos é a "abertura de perspectivas mais claras para as forças sociais empenhadas em destruir essa formação monstruosa que é o capitalismo dependente" (2005, p. 180).

Após esse levantamento sucinto das principais categorias da TMD, passaremos ao debate sobre a dependência sob a lógica da financeirização, própria da fase monopolista do capitalismo. Buscando compreender como nesta etapa foi possível a criação de "margens de manobra" para a construção das experiências alternativas contemporâneas na América Latina.

\section{DEPENDÊNCIA, CAPITALISMO MONOPO- LISTA E A ETAPA DA FINANCEIRIZAÇÃO}

\subsection{A era dos monopólios e a financeiriza- ção}

O modo de produção capitalista atraves- 
sou diferentes estágios ao longo do seu desenvolvimento histórico. A forma que hoje se desenvolvem as relações de acumulação capitalista denomina-se de capitalismo monopolista, sob hegemonia do processo de financeirização do capital. Diferentes vertentes teóricas desenvolvem leituras sobre a era dos monopólios, entretanto, pode-se dizer que há alguns consensos sobre os fatos quanto às mudanças basilares que conformam a etapa atual da economia capitalista. Para entendermos a dinâmica capitalista em sua fase monopolista e financeirizada, partimos do clássico ensaio de Paul Sweezy e Paul Baran, Capitalismo Monopolista (1966), no qual os autores analisam a experiência mais desenvolvida da sociedade capitalista monopolista, os Estados Unidos. Como Amaral (2012, p. 84) aponta sinteticamente, Sweezy e Baran "visualizam como tendências da acumulação capitalista no século XX uma queda na taxa de crescimento, uma expansão dos monopólios multinacionais e o processo de financeirização".

A origem dessas transformações, que baliza os anos 1970 como uma nova fase na economia mundial capitalista, tem suas marcas nas alterações do regime de regulação do capitalismo desde o final do século $X I X$ e o século $X X$, que leva à consolidação da hegemonia dos monopólios/sociedades anônimas, passando o capitalismo da esfera concorrencial para a monopolista (BARAN; SWEEZY, 1966). No final do século XIX, o processo de concentração de capitais leva ao processo de centralização ou monopólio. Trata-se de uma lei fundamental presente no desenvolvimento do capitalismo, a qual já fora analisada por Marx em "O capital".

O período em que houve o desenvolvimento máximo do capitalismo prémonopolista, o capitalismo em que preno- mina a livre concorrência, vai de 1860 a 1870. Lênin (2012) destaca que na época do florescimento do livre comércio, os dirigentes políticos burgueses da Inglaterra (potência hegemônica da época) eram contra a política colonial, até meados de 1860 . Com o aumento da concorrência enfrentado pela Inglaterra no mercado mundial, a salvação estaria no monopólio, "diziam os capitalistas, ao fundar cartéis, sindicatos, trustes. A salvação está no monopólio, repetiam os chefes políticos da burguesia, apressandose em se apoderar das partes do mundo ainda não repartidas" (Ibid., p. 112). Nesse sentido, o período inicial dos monopólios remonta aos cartéis, no final do século XIX, processo que ganhou força com a depressão internacional da indústria em 1870. Com o craque de 1873 e posterior crescimento, a prática dos cartéis foi amplamente utilizada no breve ascenso de 1889 e 1890. A partir dos cartéis, a vida econômica passa a ser balizada pelos mesmos, sendo que estes conquistam, uma após a outra, todas as esferas industriais e, posteriormente, a esfera financeira.

Outra característica importante assinalada por Lênin, já que queremos compreender o papel das economias dependentes no capitalismo contemporâneo, é a centralidade da política colonial no capitalismo monopolista. Lênin (2012) ressalta que as relações entre os grupos capitalistas se estabelecem, nesse período histórico, com base na partilha econômica do mundo. Em ligação com isso, se estabelecem relações entre grupos políticos, entre os Estados, baseadas na partilha territorial do mundo, na luta pelas colônias, na luta 'pelo território econômico'. Essa característica é central na fase do capitalismo monopolista, a constituição de um sistema econômico mundial pe- 
la divisão internacional do trabalho, na qual as economias dependentes e as economias centrais desenvolvem diferentes funções no que tange ao processo de acumulação. Netto e Braz (2012) sintetizam que:

No curso de sua mundialização, o capitalismo induziu a uma divisão internacional do trabalho, com espaços nacionais especializando-se (sob o comando do capital) em determinados tipos de produção. Por isso mesmo, o desenvolvimento do capitalismo, do ponto de vista internacional, resultou sempre numa determinada hierarquização entre os países, com os mais desenvolvidos estabelecendo as relações de domínio e exploração sobre os menos desenvolvidos (2012, p. 199).

Em suma, o capitalismo em sua fase monopolista se caracteriza pela fusão entre o capital industrial e o capital bancário, com alto grau de concentração e centralização, em capital financeiro. Essa fusão ocorre, muitas vezes, mediante o compartilhamento de pessoal da gestão das diretorias dos bancos e indústrias, centralizando ainda mais as atividades ligadas ao capital bancário e industrial, originando uma oligarquia financeira. Essa oligarquia financeira passa a gerir o capital e a produção centralizada e também a exportação de capitais, mediante a partilha do mundo, com já supracitado (LENIN, 2012).

Com a crise do padrão keynesianofordista, as transformações no modo de produção capitalista resultaram, a partir da década de 1970, na etapa contemporânea que é caracterizada por Foster e McChesney (2012) como monopólico-financeira e por alguns autores como o novo imperialismo (HARVEY, 2005), resultante do processo de mundialização do capital (CHES-
NAIS, 1997). Nessa etapa, o elemento dominante é o mundo dos grandes negócios organizado em empresas gigantes, que tem como lócus o processo de acumulação de capital.

Após estas breves considerações no que tange a formação dos monopólios, trataremos, a seguir, das mudanças a partir dos anos 1970. Essas são analisadas por diferentes teóricos, que compartilham a percepção de que estas transformações tiveram um grande impacto político e econômico no que tange à configuração da ordem internacional. Entre elas, explanaremos, de maneira sucinta, alguns elementos. Em seguida, procuraremos tratar do papel das economias dependentes nessa nova fase do capitalismo.

O que nos interessa são as mudanças que ocorreram a partir da década de 1970, que deram fim aos 'anos de ouro', período de grande crescimento econômico logo após o fim da II Guerra Mundial. Mas é necessário retomar alguns traços do momento que antecede a década de 1970, para compreensão do cenário.

No final da II Guerra Mundial, as mudanças que ocorreram, a partir de Bretton Woods, levaram à constituição de uma nova ordem monetária internacional, com a vigência do padrão monetário dólar-ouro e de um regime de câmbio fixo. Nesse momento também se constituem órgãos reguladores da governança internacional do sistema imperial, como a Organização das Nações Unidas (ONU) no campo político, o General Agreement on Tariffs and Trades (GATT), no campo comercial, o Fundo Monetário Internacional (FMI), para ajustamento de desequilíbrios das balanças de pagamentos e o Banco Mundial (BM), para financiamento do desenvolvimento. A cria- 
ção dessas instituições e a vigência do padrão dólar-ouro são fatores-chave para a hegemonia norte-americana, tendo em vista o importante papel da institucionalização de normas e a criação de consenso no que tange à garantia dessa hegemonia.

Segundo Ruggie (1982) o período em questão pode ser chamado de liberalismo enclausurado (embedded liberalism), ou seja, vigora um compromisso comum na ordem internacional que implica uma organização em torno de princípios liberais, porém com algumas restrições importantes: ao mesmo tempo em que incentiva-se a liberdade comercial e a exportação do capital produtivo, é permitido ao Estado nacional ter liberdade para garantir políticas sociais e intervir nas economias para manutenção do pleno emprego, o que pode ser conseguido por um maior controle sobre a conta de capital do balanço de pagamentos e por políticas ativas de gastos públicos. Esse período é marcado por uma expansão da exportação do capital produtivo, que passa a exercer um papel de força social líder do bloco histórico fordista. Nesse momento, sob a hegemonia americana, houve uma convergência entre a hegemonia, propósito social vigente e o regime monetário internacional, no Acordo de Bretton Woods. As instituições da governança internacional operam no marco discursivo na ordem do liberalismo enclausurado.

A grande onda de expansão econômica esgota-se no final dos anos 1960, quando há uma queda nos índices de crescimento econômico. Os déficits gêmeos da economia americana, como apontado pelo Dilema de Triffin, dificultam que o dólar mantenha seu poder de ordenação dos movimentos comerciais e financeiros no mundo sob o regime monetário em vigor, baseado no padrão dólar-ouro e no regime de câmbio fixo. Diante da crise, em 1971 Nixon suspende a vigência do padrão dólar-ouro, seguida por uma desvalorização do dólar e o rompimento com regime de câmbio fixo, passando para o regime de câmbio flexível.

Isto levará a alterações no bloco histórico, com a emergência da finança como elemento decisivo da dinâmica da acumulação e como força social líder. Aqui trata-se de pensar, nos termos propostos pela perspectiva neograsciana da Economia Política Internacional (COX, 1981), a emergência de um bloco histórico que altera o consenso do pós-guerra, a medida que opera pela desregulamentação financeira e pela abertura das contas de capital dos balanços de pagamentos. Com a emergência da finança, progressivamente o poder decisório irá deslocar-se da esfera estatal/governamental para o mercado, e do plano doméstico para o plano externo, onde operam de forma assimétrica em termos de poder as forças do capital monopolista.

Num processo dialético, é a exportação do capital produtivo que gera sua posterior subsunção ao capital financeiro, por meio da centralização e concentração do capital, como apontara Marx. Com a crise e uma longa onda recessiva, o excedente resultante da internacionalização do capital produtivo antes de 1970 encontra problemas para sua realização. Neste sentido, com a desregulamentação e liberalização financeira, esse excedente gerado na esfera produtiva é realizado na esfera financeira. $O$ choque do petróleo vem logo em seguida, com o aumento do preço estipulado pela Organização dos Países Exportadores de Petróleo (OPEP). O excedente líquido gerado por esse choque de preços torna-se crédito disponível no sistema. Com a expansão do 
crédito e as facilidades no fornecimento de empréstimos, os países periféricos iniciam um processo de endividamento externo, que resultará na "década perdida", como é considerada a década de 1980. Como cita Wallerstein (2004, p. 25): "o dinheiro voltou para o Terceiro Mundo (e para os países do bloco soviético) na forma de empréstimos que permitiram a esses países equilibrar temporariamente seus orçamentos, continuando a importar manufaturas ocidentais. A conta ia ser cobrada nos anos 80 ." E foi.

Para Ruggie (1982), as mudanças pós 1970 não resultaram em uma mudança do marco normativo vigente desde 1945 . Ou seja, ocorreria uma mudança nos componentes instrumentais da ordem econômica (regime cambial, padrão monetário), nos regimes de dinheiro e comércio, mas não nas normas e princípios embutidos no regime e relacionados com o propósito social. Ou seja, para Ruggie (1982) as mudanças pós- 1945 não resultariam em uma mudança de regime.

Apesar da robusta e perspicaz análise do autor sobre o período que se inicia em Bretton Woods, considera-se aqui que sua análise subestima a mudança política decorrente das alterações na dinâmica da acumulação, bem como suas consequências sociais. A financeirização alterará o contrato social do pós-guerra, alterará de forma intensa a repartição do excedente entre as diferentes classes sociais e produzirá uma alteração, mesmo que adaptativa, das instituições da governança internacional. Não menos importante, terá impactos na divisão internacional do trabalho, que vista sob uma perspectiva de longa duração, tende a deslocar o capital produtivo, a produção do valor industrial com maior agregação para a Ásia e reconduzir à condição colonial, portanto neocolonial, as regiões africana e latinoamericana. Portanto, destaca-se que não se trata de uma mudança no regime, como quer Ruggie (1982), mas de regime, embora dentro de um mesmo modo de produção capitalista. Esta alteração já decorre há quatro décadas e meia, desde os anos 1970, e coincide com a interrupção dos processos de substituição de importações na América Latina, com a crise fiscal do Estado e que o encilhamento financeiro crescente das famílias e dos governos, por meio de um processo de financeirização da lógica de funcionamento do sistema. O recente ciclo de coalisões progressista de poder na América Latina, representou uma tentativa de reverter as consequências sociais deste processo de inserção subordinada, e como veremos, com resultados positivos em alguns aspectos, mas ainda insuficientes do ponto de vista de alterações estruturais de longa duração.

Para Foster e McChesnay (2012), inspirados em Sweezy e Baran, a tendência ao crescimento do excedente na era dos monopólios resulta na sobreacumulação de capital sob a forma líquida. Esse excedente não podendo ser realizado na esfera da produção, gera simultaneamente estagnação, desigualdade e financeirização. Esta última é a saída para a realização desse excedente. $\mathrm{O}$ autor mostra que a economia se torna dependente da financeirização. Foster e McChesney (2012, p.15) apontam que:

In fact, a dangerous feedback loop between stagnation and financial bubbles has now emerged, reflecting the fact that stagnation and financialization are increasingly interdependent phenomena: a problem that we refer to in this book as the stagnation-financialization trap. 
Foster e McChesney ainda destacam que a economia capitalista mundial está enfrentando a ameaça de uma estagnação econômica de longo prazo (tendência da era dos monopólios). Ele aponta que as economias avançadas, após a queda do crescimento na década de 1970, não conseguiram retomar as taxas de crescimento anteriores. Em dados (p. 15, 2012), a taxa acumulada de crescimento dos Estados Unidos entre 2000-2011 foi 63\%, abaixo do crescimento da década de 1960. Após 1970, com a desaceleração da economia, o crescimento da dívida aparece como o instrumento para sustentar a economia norteamericana. A economia torna-se dependente da elevação dos gastos do governo e da promoção de crédito, que gera um alto endividamento das famílias, fruto da queda contínua da renda que se acentua com o deslocamento da produção do valor para a Ásia e das desregulamentações competitivas: comercial, financeira e produtiva.

The fact that the overall performance of the economy in recent years has not been much worse than it actually has been, or as bad as it was in the 1930S, is largely owing to three causes: (1) the much greater role of government spending and government deficits; (2) the enormous growth of consumer debt, including residential mortgage debt, especially during the 1970s; and (3) the ballooning of the financial sector of the economy which, apart from the growth of debt as such, includes an explosion of all kinds of speculation, old and new, which in turn generates more than a mere trickledown of purchasing power into the "real" economy, mostly in the form of increased demand for luxury goods (FOSTER;
MCCHESNEY, 2012, p. 24-5).

É importante compreender que o novo estágio do capitalismo traz a financeirização como mudança estrutural central. Entretanto, mudanças na esfera produtiva também configuram a transformação das relações econômicas. Visualiza-se a reestruturação produtiva, que contém a flexibilização nos processos de trabalho, surgimento de setores de produção novos com o desenvolvimento da Tecnologia de Informação e Comunicação (TIC), a desterritorialização da produção (HARVEY, 1993); mudanças essas que se conectam com a hegemonia e autonomização da esfera financeira, dando o tom dessa nova etapa do capitalismo mundial.

\subsection{Dependência e financeirização. 0 que muda?}

Segundo Amaral (2012, p. 5), essa nova fase do capitalismo, com centralidade na valorização fictícia do capital a partir de 1970-80, se constituiria uma "nova etapa da dependência, vinculada às transformações que se processam no capitalismo nesse período". A partir, principalmente da chamada década perdida $(1980)^{4}$, as economias de-

\footnotetext{
${ }^{4}$ Perry Anderson explica como as medidas neoliberais passam a ser implementadas nos Estados da OCDE, a partir da crise de 1973: "A chegada da grande crise do modelo econômico [...], quando todo o mundo capitalista avançado caiu numa longa e profunda recessão, combinando, pela primeira vez, baixas taxas de crescimento com altas taxas de inflação, mudou tudo. A partir daí as ideias neoliberais passaram a ganhar terreno. As raízes da crise, afirmavam Hayek e seus companheiros, estavam localizadas no poder excessivo e nefasto dos sindicatos, e de maneira mais geral, do movimento operário, que havia corroído as bases da acumulação capitalista[...]. O remédio, então, era claro: manter um Estado forte, sim, em sua capacidade de romper o poder dos sindicatos e no controle do dinheiro, mais parco em todos os gastos sociais e nas intervenções eco-
} 
pendentes foram atingidas mais gravemente, sobretudo em função da crise da dívida. Foi posta em prática uma série de ajustes ${ }^{5}$ de cunho estrutural, medidas que compõem o Consenso de Washington. Segundo Amaral (2012) essa nova fase de dependência seria marcada pela alteração no eixo de acumulação que passa da esfera produtiva para a esfera financeira, e teria como eixo central o alto nível de endividamento das economias dependentes em decorrência da alta liquidez internacional que marcou a década anterior.

Foster e McChesney (2012) assinalam que na etapa do capitalismo "monopolistafinanceiro", na qual as economias centrais estão presas na supracitada armadilha da "estagnação-financeirização", as economias dependentes cumprem um papel importante no processo de desterritorialização da produção. Os monopólios passam a explorar as diferenças nos níveis salariais, para

nômicas. A estabilidade monetária deveria ser a meta suprema de qualquer governo. Para isso, seria necessária uma disciplina orçamentária, com a contenção dos gastos com o bem-estar, e a restauração da taxa 'natural' de desemprego, ou seja, a criação de um exército de reserva de trabalho para quebrar os sindicatos" (ANDERSON In SADER 1995, p. 10-1).

${ }^{5}$ Aqui chamamos de ajustes o que, na linguagem liberal, é nomeado de reformas. Coutinho (2010, p. 35) aponta que a palavra reforma sempre foi ligada a luta dos subalternos, adquirindo uma conotação claramente progressista na linguagem política. Entretanto, "o neoliberalismo busca utilizar a seu favor a aura de simpatia que envolve a ideia de 'reforma'. É por isso que as medidas por ele propostas e implementadas são mistificadoramente apresentadas como 'reformas', isto é como algo progressista em face do estatismo, que, tanto em sua versão comunista como naquela social-democrata, seria agora inevitavelmente condenada à lixeira da história. Desta maneira, estamos diante da tentativa de modificar o significado da palavra 'reforma': o que antes da onda neoliberal queria dizer ampliação dos direitos, proteção social, controle e limitação do mercado, etc., significa agora cortes, restrições, supressão desses direitos e desse controle". extrair superlucros, que são acumulados nos núcleos orgânicos dos monopólios nos países centrais. A centralidade da exploração do exército industrial de reserva e da exploração das diferenças salariais nas economias dependentes/emergentes, pelas empresas gigantes, é um traço apontado por Foster e McChesney (2012) e por Carcanholo (2013). Foster e McChesney (2012) denominam de "arbitragem do trabalho global" este processo de exploração da força de trabalho dos países dependentes, considerado este um mecanismo de contratendência à estagnação do capitalismo monopolista.

Por fim, entre esses novos elementos da dependência já citados, é importante ressaltar a eliminação do controle de capitais, a desregulamentação e a abertura que levam a uma elevação hierárquica do setor financeiro. A financeirização se torna tão central, no sentido da sua hegemonia sob a esfera produtiva que passa a constituir um "novo guia ou um novo fator determinante e condicionador da capacidade de crescer (e se desenvolver) das economias periféricas" (AMARAL, 2012, p. 115), sendo esse guia o rentismo. Neste sentido, o Estado passa a ser dominado pela aristocracia financeira.

\section{AS ATUAIS EXPERIÊNCIAS LATINO- AMERICANAS: CONSTRUÇÃO DE 'MARGEM DE MANOBRA' FRENTE AOS CONDICIO- NANTES ESTRUTURAIS DA DEPENDÊNCIA}

Dentro desse contexto, no final da década de 1990 a América Latina passa por experiências que se configuram como tentativas de resistência ao fenômeno liberalizante, direcionadas à busca por autonomia, seja ela de forma associada a outras potên- 
cias emergentes do século $\mathrm{XXI}^{6}$, por meio da busca de um modelo próprio de desenvolvimento ou com um direcionamento de enfrentamento mais direto aos interesses imperialistas ${ }^{7}$. Esta dinâmica de alteração do quadro político regional deu-se no contexto de crise das políticas neoliberais de ajustamento estrutural (COELHO, 2012) e de ascensão de forças de esquerda e centroesquerda aos governos de diferentes países na América Latina. Este quadro de chegada ao poder foi facilitado, num primeiro momento, por uma janela de oportunidade concreta que foi a elevação do preço das commodities, diminuindo o problema crônico de restrição orçamentária e de balanço de pagamentos das economias subdesenvolvidas. Estes novos governos, com maior ou menor ênfase, convergiram para a questão da integração regional como um aspecto central de ganho de autonomia frente ao processo de globalização.

Assim, dentro deste reordenamento político latino-americano, promoveram-se novos processos de cooperação internacional e novos processos de integração regional que demonstraram a centralidade que a América Latina passa a ter na agenda da política externa de alguns países (com destaque para Brasil, Venezuela, Argentina, Uruguai, Bolívia e Equador). Esses arranjos fortalecem a unidade latino-americana e a compreensão de que a concertação regio-

\footnotetext{
${ }^{6}$ Como demonstra a associação do Brasil com a Rússia, China, Índia e África do Sul no BRICS e com a Índia e a África do Sul, no IBAS.

${ }^{7}$ Como representa o projeto político da Aliança Bolivariana para os Povos de Nossa América (ALBA), protagonizado pela política externa da Venezuela, e que surge em oposição à proposta da Área de Livre Comércio das Américas (ALCA), protagonizado pelos interesses comerciais dos Estados Unidos para a região latinoamericana.
}

nal poderia configurar-se como instrumento na busca por autonomia. Entre esses processos de integração destacam-se a União das Nações Sul-Americanas (UNASUL) e a Aliança Bolivariana para os Povos de Nossa América (ALBA). A legitimidade desse processo político se dá no sentido de que "no projeto de futuro indefinido, o olhar favorável ao continente apoia-se [...] no reconhecimento de que aqui se trava uma bataIha própria por formas alternativas de hegemonia, liderada por governos progressistas" (SARTI, 2010, p. 178).

Esses novos arranjos em nível regional foram protagonizados por projetos políticos de Estados que se colocavam enquanto lideranças regionais e que tinham governos que convergiam em alguns propósitos básicos da integração e da inserção externa regional. Nesses termos destacam-se, o Brasil, de Lula, o qual exercia uma liderança pelo peso econômico que é inquestionavelmente determinante na região, e a Venezuela, de Chávez, que assumia uma liderança ideológica, definida pelo forte enfrentamento à ofensiva neoliberal no subcontinente latinoamericano, mais explicitamente aos Estados Unidos. Sinteticamente, Brasil e Venezuela foram os dois Estados que representaram projetos políticos de integração e inserção internacional que eram convergentes no curto prazo e eventualmente divergentes numa perspectiva mais estrutural de alteração da correlação de forças internacional. Por um lado, tem-se a UNASUL que foi em grande medida resultado de um desenho geopolítico brasileiro, numa estratégia paulatina de integração com uma perspectiva moderada de integração sem confrontação direta e contínua com o império. Por outro lado, a ALBA, que já carregava em sua sigla clara contraposição em relação ao projeto 
neoliberal da ALCA. A ALBA teve na Venezuela seu nascedouro intelectual e político e se sustenta na construção de um discurso anti-imperialista, o do "Socialismo do século $\mathrm{XXI}^{8 \text { ", }}$ como princípio normativo.

A ALBA se expressa numa política de enfrentamento aos interesses estadunidenses na região, claramente representados pela ALCA. Porquanto, a oposição entre essas duas propostas de integração demonstra que a luta política constituiu-se a partir da disputa entre diferentes projetos políticos para a América Latina, num momento em que se abria espaço para uma afirmação mais autônoma regional. Cabe ressaltar que a própria alteração na rivalidade interestatal fruto de alterações na divisão internacional do trabalho refletiu-se politicamente na região. Embora medidas integracionistas sejam utilizadas com frequência na história latino-americana, desde o século XIX, no começo do século XXI ocorre uma mudança paradigmática que questiona o projeto dos Estados Unidos para a América Latina. De forma inédita, em alguns países, os Estados Unidos já deixaram de ser o Estado protagonista na balança comercial; como é o caso do Brasil que, desde 2012, passou a ter a China enquanto maior participante no volume de exportações do país 9 .

Nessa conjuntura de alterações na política regional no início do século XXI, Katz

${ }^{8}$ Conceito de redefinição do socialismo que rejeita o centralismo das experiências do socialismo real. Introduzido na América Latina por líderes como Hugo Chávez, Rafael Correa e Evo Morales, busca resolver problemas urgentes como a pobreza, fome, exploração, opressão econômica, racismo, sexismo e a destruição de recursos naturais, partindo da construção de uma democracia planificada.

9 Segundo dados do "Brazilian Trade Balance: Consolidated Data". Ministério do Desenvolvimento, Indústria e Comércio Exterior. 2012. Retrieved 2012-04-16
(2010) aponta que haveria três projetos em disputa nos processos de integração regional em curso. O primeiro é o projeto imperial encabeçado pelos Estados Unidos, que se materializava na proposta da Alca, mas que depois de sua derrota, vem se conformando através de iniciativas de livre comércio por meio de tratados bilaterais com países como Peru, Colômbia, Chile e México. A expressão desse projeto na atualidade é a Aliança para o Pacífico, bloco comercial fundado em 2012, no qual participam os quatro países supracitados. Em segundo lugar, estaria o regionalismo de cunho neodesenvolvimentista, representado pelo Mercado Comum do Sul (Mercosul) e pela iniciativa da Unasul, que procura articular regionalmente os interesses das classes dominantes latino-americanas com a liderança da burguesia brasileira. O terceiro projeto seria o da integração bolivariana, que tem como liderança a Venezuela, acima descrito.

A análise de Katz (2010) demonstra como existem diferentes tons de confrontação nesses arranjos regionais construídos em meio à conjuntura econômica favorável para a América Latina. A principal experiência impulsionada por esse boom das commodities pode ser observada nas experiências vivenciadas pela população dos países da América Andina (Equador, Venezuela e Bolívia). Gonçalves et al (2008) cita que a fase ascendente do ciclo econômico, iniciada em 2003 , com o preço elevado dos hidrocarbonetos, favoreceu esses países que vinham buscando "implementar políticas que levem à reconfiguração dos seus padrões de inserção econômica internacional, mais especificamente, à redução da vulnerabilidade externa estrutural" (2008, p.15). Essas políticas são o processo de nacionalização e esta- 
tização do gás boliviano, a estatização da PDVSA na Venezuela, a auditoria cidadã da dívida equatoriana e, por fim, a tentativa de construção de um projeto latinoamericanista por esses países, por meio do estímulo à integração regional ${ }^{10}$. As experiências vivenciadas por esses três países são as que mais apontam para a centralidade das brechas conjunturais para a construção desses projetos.

A partir desses elementos apontados, fica nítido que o cenário acima descrito não foi resultado exclusivamente da dinâmica política regional. A dimensão da economia foi determinante para permitir essas mudanças, tendo em vista as possibilidades que a conjuntura econômica favorável possibilitou para a região.

Neste sentido, Carcanholo (2013) elencam cinco componentes da dependência. Dois deles como os condicionantes estruturais da dependência, quais sejam: a transferência de valor para as economias centrais pela troca desigual e outras formas de remessa de valor enviadas às economias centrais, como pagamento de juros, transferência de lucros, entre outros. O autor aponta que a

situação concreta das economias dependentes é dada, em momentos históricos específicos, por esses condicionamentos estruturais, aliados aos determinantes conjunturais da situação externa: crescimento da economia mundial, que dá as possibilidades de mercados externos para

${ }^{10}$ Gonçalves et al. (2008, p. 16) aponta que esses três países vêm adotando medidas de apoio econômico mútuo, no qual a Venezuela tem funcionado como um 'banco central informal', se dispondo a compra de títulos das dívidas públicas nacionais dos países da região, pela suas reservas elevados, que em 2006 datavam 36 bilhões de dólares. os produtos exportados pelas economias dependentes, definindo as condições de realização do valor produzido pela economia dependente no mercado mundial; e a situação específica do mercado de crédito internacional, que define o volume de capitais externos disponível no cenário internacional passível de ser atraído para as economias dependentes a fim de financiar os problemas estruturais de contas externas, assim como o preço (taxa de juros) necessário para essa atração (2013, p. 201, grifo nosso).

Isso aponta que as economias dependentes têm determinantes estruturais que se materializam pela troca desigual, mas em alguns momentos históricos conseguem ter maior ou menor margem de manobra a partir da variação dos fatores conjunturais. Ou seja, se há um crescimento baixo e uma situação desfavorável no fornecimento de crédito, os condicionantes estruturais da dependência se acentuam. Mas, se há crescimento na economia mundial e fácil acesso ao crédito, há uma maior margem de manobra para as economias dependentes (CARCANHOLO, SALUDJIAN 2014).

A partir desses pressupostos, analisa-se que entre 2003-2007, o aumento da liquidez internacional e da demanda pelas commodities latino-americanas resultou em um cenário externo favorável para as economias dessa região. Para Paschoa e Carcanholo (2009), o aumento do preço das commodities tem relação com fatores monetário-financeiros. Os autores aventam que:

Evidentemente que a manutenção do momento de alta na liquidez internacional, ao menos até meados de 2007, conforma um excesso de capital monetário 
que procura espaços de valorização em vários mercados, sendo o de commodities alimentares um deles. Além disso, a tendência de desvalorização do dólar, que ocorreu até meados do mesmo ano, também contribuiu para a elevação dos preços das commodities. Esses fatores propiciaram uma transferência de capital fictício, e de toda a sua lógica especulativa, para os mercados futuros de commodities em geral, e de alimentos em específico (Ibid., p. 1-2).

Outro fator que incidiu nessa conjuntura está ligado à grande relevância que a China passou a apresentar na economia internacional. As demandas chinesas resultaram em um mercado essencial para as exportações latino-americanas nesse momento. Martins (2008, p. 118) cita que "a demanda por matérias-primas e bens de consumo básicos, eleva os termos de troca em favor dos produtos primários". Entre 2003 e 2007, a América Latina acumula um ingresso de US\$ 115,5 bilhões de dólares na balança de transações correntes, inédito desde 1950 (MARTINS, 2008).

Esses fatores anticíclicos contribuíram para um momento de crescimento econômico conjuntural, que gerou uma 'margem de manobra' para a introdução de políticas de combate à pobreza e de tentativa de inserção internacional autônoma de alguns países latino-americanos, por meio da construção de iniciativas no âmbito regional.

Gonçalves et. al. (2008) cita que a fase ascendente do ciclo econômico, iniciada em 2003, com o preço elevado dos hidrocarbonetos, favoreceu esses países que vêm buscando "implementar políticas que levem à reconfiguração dos seus padrões de inserção econômica internacional, mais especificamente, à redução da vulnerabilidade ex- terna estrutural" (Ibid., p.15). Essas políticas podem ser exemplificadas pela estatização da Petróleos de Venezuela, Sociedade Anônima (PDVSA), na Venezuela, e pela tentativa de construção de um projeto latinoamericanista, por meio do estímulo à integração regional.

Esses determinantes conjunturais da situação externa apontam condições importantes para o impulso ou estagnação da construção de processos por busca de autonomia na América Latina. Compreende-se que os fatores da i) conjuntura econômica e da ii) correlação das forças sociais no âmbito da política incidem, dessa forma, sobre a construção de experiências mais ou menos autônomas, em nível regional, na América Latina.

É importante destacar que, como unidade contraditória, essas experiências foram constituídas em economias nacionais onde vigora a realidade do capitalismo dependente, que determina a inserção subordinada na economia mundial, a partir do papel que ocupam na divisão internacional do trabalho. Assim, estruturalmente, a especialização produtiva com foco na pauta exportadora (OSÓRIO, 2012), aumenta a subordinação das economias latinoamericanas ao mercado externo, aprofundando sua condição dependente.

Assim, embora a janela de oportunidade tenha encontrado terreno fértil nos governos progressistas da região na primeira metade do século $X X I$, fatores estruturais da ordem internacional que reforçam a dependência não foram enfrentados. Em especial pela falta de uma política mais ativa de definição de qual integração seria a mais adequada numa perspectiva de longo prazo.

Um fator de constrangimento estrutural 
é a persistência da importância do setor primário-exportador e reprimarização da pauta de exportações das economias latinoamericanas que já haviam alcançado um grau razoável de industrialização, como é o caso do Brasil. Osorio (2013) denomina essa reprimarização como um novo padrão de reprodução de capital nas economias dependentes, porque demarca o fim do padrão industrial que vigorou na região entre 1940 e meados de 1970 . O autor categoriza como traço distintivo desse novo padrão exportador a especialização produtiva ${ }^{11}$, pois este se apoia em alguns eixos nos quais predominam bens provenientes da mineração e agricultura ${ }^{12}$.

Assim sendo, como a condição de dependência se constitui como estrutural, essas janelas de oportunidade apresentam riscos e debilidades. Neste sentido, a demanda chinesa caracteriza-se como o principal fator conjuntural e de riscos, pois grande parte da exportação das commodities está destinada ao mercado chinês. No momento em que o cenário internacional não for mais favorável para as economias dependentes todos os processos estarão sob ameaça, como está ocorrendo hodiernamente. No caso dos dois principais países da América do Sul, Brasil e Argentina, as experiências dos governos Kirchner (Fer-

${ }^{11}$ Esse novo padrão exportador de especialização produtiva diferencia-se do padrão agromineiro exportador vigente do século $X I X$ até o século $X X$, porque os bens primários agora exigem um maior grau de elaboração que o padrão agromineiro, para além da importância também dos bens industriais do ramo automobilístico e da produção eletrônica.

${ }^{12}$ A região continua sendo um abastecedor de matériasprimas e alimentos (que se convertem em capital variável). Centralidade nos produtos do agronegócio, como a soja e nos produtos com 'vantagens naturais', como o petróleo e minérios (OSORIO, 2012, p. 112). nando e posteriormente Cristina) e Lula, foram marcadas pela condução de uma política externa com elevado grau de autonomia, se comparado com os períodos dos governos anteriores de Carlos Menem na Argentina e Fernando Henrique Cardoso no Brasil.

Salta aos olhos que uma alteração importante na dinâmica política destes países, com a vitória de Mauricio Macri na Argentina e a derrubada do governo de Dilma Rousseff no Brasil, tenha levado em ambos países a uma alteração fundamental na política externa num passo acelerado. As políticas voltam à uma convergência com o eixo histórico de dominação, os EUA, no que repercute na crise vivenciada pelo governo bolivariano de Maduro na Venezuela e no congelamento dos processos de integração, sintoma inequívoco do abandono de uma perspectiva mais autônoma para a região.

Uma hipótese importante para se destacar entre a diferença dos processos políticos na Argentina e Brasil, comparativamente aos da Bolívia, Equador e Venezuela, seria o grau de associação e força das burguesias internas das maiores economias do Cone Sul. A reviravolta de suas políticas ocorre de maneira muito intensa e repercute uma reação importante das respectivas burguesias e seus extratos auxiliares, os setores da "classe média". Em ambos os países a virada política reflete em grande medida aquilo que a TMD historicamente sustenta: a incapacidade das respectivas burguesias internas em países dependentes de levar a frente reformas estruturais que rompam com os limites impostos à expansão das forças produtivas. Supomos que na fase monopólicofinanceira estes limites ganham o componente adicional que é o rentismo. A transformação das burguesias internas em uma 
classe predominantemente rentista, cujo patrimônio se sustenta progressivamente em direitos contratuais sobre a títulos da dívida soberana interna, de imóveis urbanos e rurais geradores de renda e de acesso privilegiado aos postos de trabalho com maior remuneração do serviço público. Estas característica se espalham para a classe média "poupadora e patrimonialista", aquela que é capaz de extrair renda. Este setores, como no passado, representam um forte obstáculo aos projetos de autonomia na região.

A experiência recente mostra que segue o desafio de construir-se projetos de autonomia que ataquem o problema central apontado pelos dependentistas: o controle sobre o excedente, sem o que não há projeto de autonomia possível. O desafio é conseguir exercer este controle num ambiente de acirramento da rivalidade interestatal e de agudização dos problemas de acumulação em escala global. Ressalta-se a insuficiência de mecanismos de integração capazes de diminuir o grau de influência externa regional. Afora a Bolívia, que segue um ritmo de crescimento constante e robusto, os demais países latino-americanos que compunham a experiência progressista do início do século XXI na América Latina enfrentam problemas sérios de financiamento que só tendem a se agravar desde uma perspectiva que aprofunda as políticas neoliberais de externalização da tomada de decisão por meio de concessão de direitos ao capital monopolista internacional (como se vê no caso da alteração do marco regulatório de exploração do petróleo no Brasil). As recentes medidas de flexibilização da legislação trabalhista no Brasil acentuam a característica da superexploração da força de trabalho. Nesse processo de crise das experiên- cias dos governos progressistas, não é por acaso que já se apresenta uma tendência de divisão e confronto entre os países da região, outra característica histórica da atuação imperialista na América Latina: dividir para governar.

\section{CONSIDERAÇÕES FINAIS}

A América Latina constitui-se como um importante celeiro de experiências de resistência à condição estrutural periférica de suas economias. A história da região é marcada por processos revolucionários, levantes populares, entre outras iniciativas que demonstram uma busca por construção de "margem de manobra" frente a sua inserção subordinada na divisão internacional do trabalho e as consequências para a dinâmica das sociedades de classes aqui constituídas. Sob essa perspectiva, nesse artigo buscou-se retomar a contribuição de categorias trabalhadas pelo pensamento social latinoamericano para o entendimento da condição estrutural de dependência das economias latino-americanas no capitalismo mundial para, a partir desse quadro teórico, buscar elementos para a compreensão da constituição do campo antineoliberal no início do século XXI na região.

A partir dos elementos acima articulados, compreende-se que o momento histórico que marca a guinada à esquerda dos países latino-americanos pode ser considerado um momento no qual os determinantes conjunturais da economia internacional foram favoráveis à construção de uma maior "margem de manobra" para os Estados latinoamericanos. O aumento dos preços das commodities permitiu o escoamento com preços melhores dos produtos primários das economias latino-americanas (soja, pe- 
tróleo, gás, etc) e a alteração na divisão internacional do trabalho alterou o destino geográfico da tradicional pauta exportadora latino-americana. Diante dessa condição externa favorável, constituiu-se, no âmbito da política, importantes arranjos levando à criação de uma coalisão antineoliberal, que se expressa na política institucional, na articulação de movimentos sociais, na construção de políticas sociais de combate à pobreza e à exclusão social - tendo como síntese uma série de arranjos regionais na busca por uma maior autonomia. Esses arranjos devem ser compreendidos como uma tentativa de "contornar os condicionantes estruturais de sua dependência", mas que são limitados em momentos de crise, nos quais os condicionantes voltam a exercer seu determinante estrutural.

No que tange ao caráter da resistência à essa situação estruturalmente adversa, concluímos que i) o histórico de resistência nas iniciativas e articulações regionais em torno da busca pela autonomia demonstram que a pauta da unidade latinoamericana é um projeto essencial no histórico da formação social da região e da luta por sua autonomia; ii) é notória a capacidade de resistência e de inventividade do povo latino-americano na construção de arranjos regionais anti-imperialistas; iii) em situações de aprofundamento da dependência, a articulação regional surge como possibilidade de criar mecanismos de saída às adversidades; iv) conjunturas economicamente favoráveis às economias dependentes conjugada à governos progressistas viabiliza a construção de projetos alternativos em nível regional .

Contudo, como verifica-se na experiência recente, a ausência de medidas mais efetivas de integração acaba mostrando a fragi- lidade das unidades soberanas quando da reversão do ciclo de negócios. Estas dificuldades também devem ser entendidas no âmbito da heterogeneidade em termos de produtividade e tamanho de mercado dos países da região. Além disto, especificamente sobre a experiência recente, fica claro que as coalizações de poder, em paíseschave, não foram capazes de alterar a tendência de aprofundamento de uma inserção regressiva (reprimarização).

Por fim, podemos afirmar que esses condicionantes estruturais da dependência só poderão ser enfrentados por meio da construção de programas políticos que reivindiquem reformas estruturais em conjunção com a construção de um projeto de desenvolvimento econômico que foque o fortalecimento da soberania nacional.

\section{REFERÊNCIAS BIBLIOGRÁFICAS}

AMARAL, Marisa Silva. Teorias do imperialismo e da dependência: a atualização necessária ante a financeirização do capitalismo. 2012. Tese (Doutorado em Economia das Instituições e do Desenvolvimento) Faculdade de Economia, Administração e Contabilidade, Universidade de São Paulo, São Paulo, 2012. Disponível em: <http:// www.teses.usp.br/teses/disponiveis/12/12 140/tde-09102012-174024/>. Acesso em 28 nov. 2016.

AMARAL, M. S.; CARCANHOLO, Marcelo. Superexploração da força de trabalho e transferência de valor: fundamentos da reprodução do capitalismo dependente. In: FERREIRA, C; OSORIO, J; LUCE, M. (Org.) Padrão de reprodução do capital: contribuições da teoria marxista da dependência. São Paulo: Boitempo, 2012.

ANDERSON, Perry. Balanço do neoliberalis- 
mo. In: SADER, Emir. Pós-neoliberalismo: as políticas sociais e o Estado democrático. Rio de Janeiro: Paz e Terra, 1995.

BARAN, Paul; SWEEZY, Paul. Capitalismo Monopolista. 2a ed. Rio de Janeiro: Zahar, 1974.

BOCCA, Pedro P. Livre-comércio dependente, lutas sociais e a formação se um campo antineoliberal na América Latina. 2013. 118 f. Dissertação (Mestrado em Ciências Sociais) - Faculdade de Ciências Sociais, Pontifícia Universidade Católica de São Paulo (PUC - SP), São Paulo, 2013.

CARCANHOLO, Marcelo. $O$ atual resgate crítico da teoria marxista da dependência. Revista Trabalho, Educação e Saúde, Rio de Janeiro, v. 11, n. 1, p. 191-205, jan./abr. 2013. Disponível em: <http://www.scielo. $\mathrm{br} / \mathrm{pdf} / \mathrm{tes} / \mathrm{v} 11 \mathrm{n} 1 / \mathrm{a} 11 \mathrm{v} 11 \mathrm{n} 1 . \mathrm{pdf}>$. Acesso em: 15 nov. 2014.

; SALUDJIAN, Alexis. Integração latino-americana, dependência da China e subimperialismo brasileiro na América Latina. In: CONFERÊNCIA INTERNACIONAL CONJUNTA FLACSO-ISA, 2014. Anais... Buenos Aires: FLACSO-ISA, Conferencia Internacional Conjunta, 2014. Disponível em: <http:// web.isanet.org/Web/Conferences/FLACSOISA\%20BuenosAires\%202014/Archive/a5eb 220d-d8b3-48f1-a256-5c5c87c3bfa2.pdf>. Acesso em: 20 jan. 2017.

CHESNAIS, François. A mundialização do capital. São Paulo: Xamã, 1997.

COELHO, Jaime Cesar. Economia, poder e influência externa: o Banco Mundial e os anos de ajuste na América Latina. São Paulo: UNESP, 2012.

COHEN, Benjamin J. International Political Economy: An Intellectual History. Princenton: Princeton University Press, 2008.

COUTINHO, Carlos Nelson. A hegemonia da pequena política. In: OLIVEIRA, Francisco de; BRAGA, R.; RIZEK, C. (Org.). Hegemonia às avessas: economia, política e cultura na era da servidão financeira. São Paulo: Boitempo, 2010.

COX, Robert. Social forces, states and world orders: beyond international relations theory. Millennium - Journal of International Studies, v. 10, n. 2, p. 126-155, 1981. Disponível em: <http://journals.sagepub.com/ doi/pdf/10.1177/03058298810100020501>. Acesso em: 15 out. 2017.

FOSTER, John Bellamy; MCCHESNEY Robert W. The Endless Crisis: How MonopolyFinance Capital Produces Stagnation and Upheaval from the USA to China. New York: Monthly Review Press, 2012.

GONÇALVES, Reinaldo et al. Vulnerabilidade Externa Estrutural da América Latina. Grupo de Trabalho CLACSO "Setores Dominantes na América Latina", $A B R / 2008$. Disponível em: <www.ie.ufrj.br/hpp/intranet/pdfs/vul nerabilidade_externa_america_latina_gep_ abril_2008.pdf> Acesso em 20 jan. 2017. HARVEY, David. O Novo Imperialismo. 2. ed. São Paulo: Loyola, 2005.

KATZ, Claudio. Tres proyectos en disputa. La página de Claudio Katz, textos de Ciencias Sociales, América Latina, 2010. Disponível em: <www.katz.lahaine.org/?p=198>. Acesso em: 10 ago. 2017.

LENIN, V. I. Imperialismo, estágio superior do capitalismo. São Paulo: Expressão Popular, 2012.

MARINI, Ruy Mauro. Subdsarollo y revolución. México: Siglo Veintiuno Editores, 1970.

- Dialética da dependência. In: TRASPADINI, R; STEDILE, J. P. (Org.). Ruy Mauro Marini: vida e obra. São Paulo: Expressão Popular, 2005.

- O ciclo do capital na economia 
dependente. In: FERREIRA, C; OSORIO, J; LUCE, M. (Org.). Padrão de reprodução do capital: contribuições da teoria marxista da dependência. São Paulo: Boitempo, 2012.

MARTINS, Carlos Eduardo. A América Latina e a Economia Mundial: Conjuntura, Desenvolvimento e Prospectiva. In: VIANA, André Rego. BARROS, Pedro Silva; CALIXTRE, André Bojikan (Org.). Governança global e integração da América do Sul. Brasília: Ipea, 2011.

MARX, Karl. O Capital. Crítica da Economia Política. Livro I; Vol. II. Rio de Janeiro: Civilização Brasileira, 2002.

NETTO, José Paulo; BRAZ, Marcelo. Economia Política: uma introdução crítica. 7. ed. São Paulo: Cortez, 2011.

OSORIO, Jaime. América Latina: o novo padrão exportador de especialização produtiva - estudo de cinco economias da região. In: FERREIRA, C; OSORIO, J; LUCE, M. (Org.). Padrão de reprodução do capital: contribuições da teoria marxista da dependência. São Paulo: Boitempo, 2012.

PASCHOA, Juan Pablo Painceira. CARCANHOLO, Marcelo. Crise alimentar e financeira. A lógica especulativa atual do capital fictício. In: XXVII CONGRESO DE LA ASOCIACIÓN LATINOAMERICANA DE SOCIOLOGÍA. VIII JORNADAS DE SOCIOLOGÍA DE LA UNIVERSIDAD DE BUENOS AIRES. BuenoS Aires: Asociación Latinoamericana de Sociología, 2009. Disponível em: <http://www. aacademica.org/000-062/1025.pdf>. Acesso em: 20 set. 2016.

RUGGIE, John Gerard. International regimes, transactions, and change: embedded liberalism in the postwar economic order. International Organization, Volume 36, Issue 2, International Regimes (Spring, 1982), 379-415.

SARTI, Ingrid. A arquitetura política e os desafios da institucionalidade na integração Sul-americana. In: CERQUEIRA FILHO, Gisálio (Org.). Sulamérica, comunidade Imaginada. Emancipação e integração. XI Congresso Internacional do FoMerco. Niterói : EdUFF, 2011, pp. 177-192.

SANTOS, Theotonio. A teoria da dependência: um balance histórico e teórico. Disponível em: <http://www.reggen.org.br/midia/ documentos/ateoriadadependencia.pdf $>$. Acesso em: 28 jan. 2017.

WALLERSTEIN, Immanuel. O declínio do poder americano. São Paulo: Contraponto, 2004.

Artigo recebido em 01 de novembro de 2017.

Aprovado em 29 de novembro de 2017. 